\title{
Effect of Heavy Metals on, and Handling by, the Kidney
}

\author{
Olivier Barbier Grégory Jacquillet Michel Tauc Marc Cougnon \\ Philippe Poujeol
}

Unité Mixte de Recherche-Centre National de la Recherche Scientifique 6548,

Université de Nice-Sophia Antipolis, Nice, France

\section{Key Words}

Cadmium $\cdot$ Renal transport $\cdot$ Nephron $\cdot$ Acute

intoxication $\cdot$ Chronic intoxication $\cdot$ Nephrotoxicity

\begin{abstract}
Heavy metals such as cadmium $(\mathrm{Cd})$, mercury $(\mathrm{Hg})$, lead $(\mathrm{Pb})$, chromium $(\mathrm{Cr})$ and platinum $(\mathrm{Pt})$ are a major environmental and occupational hazard. Unfortunately, these non-essential elements are toxic at very low doses and non-biodegradable with a very long biological halflife. Thus, exposure to heavy metals is potentially harmful. Because of its ability to reabsorb and accumulate divalent metals, the kidney is the first target organ of heavy metal toxicity. The extent of renal damage by heavy metals depends on the nature, the dose, route and duration of exposure. Both acute and chronic intoxication have been demonstrated to cause nephropathies, with various levels of severity ranging from tubular dysfunctions like acquired Fanconi syndrome to severe renal failure leading occasionally to death. Very varied pathways are involved in uptake of heavy metals by the epithelium, depending on the form (free or bound) of the metal and the segment of the nephron where reabsorption occurs (proximal tubule, loop of Henle, distal tubule and terminal segments). In this review, we address the
\end{abstract}

putative uptake pathways involved along the nephron, the mechanisms of intracellular sequestration and detoxification and the nephropathies caused by heavy metals. We also tackle the question of the possible therapeutic means of decreasing the toxic effect of heavy metals by increasing their urinary excretion without affecting the renal uptake of essential trace elements. We have chosen to focus mainly on $\mathrm{Cd}, \mathrm{Hg}$ and $\mathrm{Pb}$ and on in vivo studies.

Copyright $(2005$ S. Karger AG, Basel

\section{Introduction}

Divalent cations are essential to cell homeostasis. Among these cations trace elements as $\mathrm{Zn}^{2+}, \mathrm{Fe}^{2+}$ and $\mathrm{Cu}^{2+}$ participate in the regulation of numerous physiological functions (e.g. nucleic acid and protein synthesis, enzymatic reactions, membrane stabilization, immune system function, antioxidant defenses, oxidative phosphorylation, etc.). These metals are effective at very low concentrations, and their concentration in body fluids must be tightly regulated: deficiency or excess both cause severe illness and death. Thus, urinary excretion by the kidney, together with the gastrointestinal absorption rate, plays an important role in regulating the plasma level of

\section{KARGER \\ Fax +4161306 1234 E-Mailkarger@karger.ch} www.karger.com
(C) 2005 S. Karger AG, Basel $1660-2137 / 05 / 0994-0105 \$ 22.00 / 0$

Accessible online at:

www.karger.com/nep
Dr. Philippe Poujeol

UMR-CNRS 6548, Bâtiment Sciences Naturelles

Université de Nice-Sophia Antipolis, Parc Valrose

FR-06108 Nice Cedex 2 (France)

Tel.+33492076852, Fax +33492076850, E-Mail poujeol@unice.fr 
these elements. Although the renal handling of cations is not fully understood, it is probable that each segment of the nephron is involved in their reabsorption, even so $70 \%$ of the transport occurs along the proximal tubule [6]. Over the past decade, our knowledge of divalent cation transport has been considerably advanced by the molecular cloning of the divalent metal transporter 1 (DMT1). DMT1 was identified first in the gastrointestinal tract and is clearly involved in the transport of trace elements. DMT1 is highly expressed in renal tissue [7] and is therefore a good candidate for trace element transport. Unfortunately, DMT1 is also involved in the transport of some highly toxic divalent cations such as $\mathrm{Cd}^{2+}, \mathrm{Pb}^{2+}, \mathrm{Co}^{2+}$, $\mathrm{Ni}^{2+}$ and $\mathrm{Pt}^{2+}$. Therefore, when the body is contaminated with these poisons the kidney will be confronted with two problems: (1) the entry of the toxic metal into the renal cells and (2) the concomitant decrease of the essential trace element entry due to competition with the toxin. However, DMT1 is probably not the only renal transporter involved in toxic metal transport. There is evidence that $\mathrm{Zn}^{2+}$ could also be transported in the proximal tubule complexed with cysteine or histidine via a sodiumamino acid cotransporter [8] and toxic metals might bind these amino acids and compete with $\mathrm{Zn}^{2+}$. This is particularly the case for $\mathrm{Hg}^{2+}$ and $\mathrm{Cd}^{2+}$ which easily form cysteine conjugates. Such examples of interactions between a toxic heavy metal and its non-toxic homologue underline the necessity of elucidating their transport systems.

In this review, we address the transport mechanisms of toxic heavy metals (mainly $\mathrm{Cd}^{2+}, \mathrm{Pb}^{2+}$ and $\mathrm{Hg}^{2+}$ ) along the different segments of the nephron. This has been done on the basis that a decreased toxic effect can be achieved by increased urinary excretion of heavy metals without a modification in the reabsorption of essential trace elements. For this reason, we have focused our review mainly on in vivo studies.

\section{What Are the Chemical Forms of Heavy Metal Filtered by the Glomerulus?}

As divalent cations, plasma heavy metals (toxic or not) exist as non-diffusible (protein-bound) and diffusible (complexed and ionized) forms. Tubular reabsorption will depend on the main form present in the glomerular ultrafiltrate. In turn, the ultrafiltrate composition will depend on the dosage and the mode of intoxication. Many accidental intoxications are due to absorption of heavy metal salt leading initially to an increase of the inorganic form in the plasma. Heavy metal ions bind rapidly to albumin, the most abundant protein in plasma. The affinity to albumin is probably not the same for all the heavy metals. They readily bind to the free sulfhydryl group of terminal cysteine residues and to histidine residues [7]. However, a small fraction escapes to this binding and the plasma also contains the free form of the heavy metal. Since a small fraction of albumin is always filtered by the glomerulus, luminal fluid delivered to the early proximal tubule will contain both albumin-bound heavy metal and the ionized form. This situation arises primarily in cases of acute intoxications. It is noteworthy that after systemic injection of a single dose of $\mathrm{Cd}^{2+}$, the heavy metal is rapidly cleared from the blood although urinary excretion of $\mathrm{Cd}^{2+}$ remains undetectable [O.B., unpubl. data]. This indicates that under these conditions the entire bulk of the injected metal is quickly sequestered by different tissues, mainly in the liver (60-80\%) and the kidney [8, and O.B., unpubl. data]. Finally, renal uptake following acute intoxication is probably due to the membrane transport of both albumin-bound and free forms of heavy metals. During chronic intoxication, the concentration of heavy metal-binding proteins increases in the blood. Heavy metals are known to be potent inducers of metallothioneins and glutathione in renal and liver tissues [19]. Their synthesis is induced by the free form of the heavy metal [10]. Metallothioneins are low weight cysteine-rich proteins and glutathione is a tripeptide containing one cysteine. Both peptides, synthesized in the liver and the kidney, protect against heavy metal toxicity by trapping the metal inside the cells by conjugate formation [19]. The renewal of liver cells during intoxication leads to the release of these conjugates into the systemic circulation where they are subsequently delivered to the kidneys [17].

\section{What Are the Chemical Forms of Heavy Metal Transported in the Kidney?}

As discussed above, heavy metals are present in the tubular fluid under free and bound forms.

Transport of Ionized Forms. The ionized forms of toxic heavy metals are present during acute intoxication. Owing to their properties to form complex or conjugate in the blood, the concentration of the free ionized forms represents less than $10 \%$ of the total metal concentration. Clearance measurements in the rat showed that during acute intoxication $99 \%$ of filtered $\mathrm{Cd}^{2+}$ was absorbed [1]. Other studies have demonstrated that $\mathrm{Hg}^{2+}$ and $\mathrm{Pb}^{2+}$ are 
subject to similar renal handling. Finally, in the kidney, heavy metals are primarily absorbed through the apical membrane and do not readily exit from the basolateral membrane. For instance, less than $10 \%$ of the $\mathrm{Hg}^{2+}$ taken up from luminal side appears on the basolateral side [19]. This is also the case for $\mathrm{Cd}^{2+}$, which is undetectable in the peritubular capillary after being microinjected into the lumen of the nephron [1].

Techniques such as micropuncture, microinjection [1, $6,18]$ and microperfusion of isolated tubules [14] have made it possible to map the reabsorption of the heavy metals along the different segments of the nephron.

Proximal Tubule. Using ${ }^{109} \mathrm{Cd}$ microinjections into the rat proximal tubule, Felley-Bosco and Diezi [6] and Barbier et al. [1] found that 70 and $95 \%$, respectively, of injected ${ }^{109} \mathrm{Cd}$ was taken up by the proximal tubule. The addition of $\mathrm{Fe}^{2+}, \mathrm{Co}^{2+}$ or $\mathrm{Zn}^{2+}$ to the microinjection decreased proximal $\mathrm{Cd}$ reabsorption. Conversely, $\mathrm{Cd}^{2+} \mathrm{de}-$ creased proximal reabsorption of microinjected ${ }^{65} \mathrm{Zn}$ [1]. Taken together, these data suggest common competitive transcellular pathways for divalent metals in the proximal tubule. In recent years, molecular and cellular biology techniques have been used to identify transporters involved in the reabsorption of ionized forms. The first heavy metal transporter was described by Palmiter and Findley [15] and known as ZnT1 (zinc transporter 1). In addition to $\mathrm{Zn}^{2+}$, $\mathrm{ZnT} 1$ could also transport $\mathrm{Cd}^{2+}$ and $\mathrm{Cu}^{2+}$ with a low affinity. However, it is mainly located in the basolateral membrane. Among the transporters, DMT1 could mediate $\mathrm{Fe}^{2+}, \mathrm{Zn}^{2+}, \mathrm{Mn}^{2+}, \mathrm{Cd}^{2+}, \mathrm{Pb}^{2+}, \mathrm{Co}^{2+}$, $\mathrm{Ni}^{2+}$ and $\mathrm{Pt}^{2+}$ reabsorption, but its expression in the apical membrane of the proximal tubule remains controversial. The 'zinc transporters' belonging to the Zrt, IRT-like protein (ZIP) family, involved in the uptake of $\mathrm{Zn}^{2+}, \mathrm{Fe}^{2+}$, $\mathrm{Co}^{2+}$ and $\mathrm{Cu}^{2+}$ or the ATP-binding cassette (ABC) type transporter family, involved in the uptake of $\mathrm{Ni}^{2+}, \mathrm{Mn}^{2+}$, $\mathrm{Fe}^{2+}$ and $\mathrm{Mo}^{2+}$, could also be candidates. However, their expression in the kidney has not been clearly demonstrated. Stretch-activated cation channels (SAC) could also be involved in the uptake of heavy metal divalent forms since Barbier et al. [1] have demonstrated the existence of proximal uptake of $\mathrm{Cd}^{2+}$ sensitive to gadolinium $\left(\mathrm{Gd}^{3+}\right)$. These examples demonstrate that heavy metals could be transported by a large variety of transporters in the proximal tubule; the involvement of each remains to be elucidated.

Loop of Henle and Terminal Segment (Distal Tubule and Connecting Tubule). Although the proximal tubule is the main site of reabsorption, downstream segments of the nephron also exhibit a high permeability for essential and toxic metals. Wareing et al. [18] demonstrated that the loop of Henle (LH) and the terminal segments could participate in $\mathrm{Fe}^{2+}$ reabsorption. $\mathrm{Zn}^{2+}$ and $\mathrm{Cd}^{2+}$ are also transported in these segments [1]. In the LH, transcellular and paracellular pathways are probably both involved in the transport of heavy metals [1]. The paracellular passive reabsorption of cations is driven by a lumen-positive voltage generated by apical $\mathrm{Na}^{+} \mathrm{K}^{+} 2 \mathrm{Cl}^{-}$cotransport and $\mathrm{K}^{+}$ recycling. Microinjections of ${ }^{55} \mathrm{Fe}$ by Wareing et al. [18] suggest that, in the $\mathrm{LH}, \mathrm{Fe}^{2+}$ is taken up by the DMT1 transporter. This transporter has been localized in the apical membrane of the $\mathrm{LH}$, the DCT and the collecting ducts [7]. The role of DMT1 in $\mathrm{Cd}^{2+}$ reabsorption has been demonstrated by Barbier et al. [1] using ${ }^{109} \mathrm{Cd}$ microinjections. They showed that $\mathrm{Fe}^{2+}, \mathrm{Co}^{2+}$ and $\mathrm{Zn}^{2+}$ decreased ${ }^{109} \mathrm{Cd}$ uptake in both $\mathrm{LH}$ and distal tubule (DT). Furthermore, Leazer et al. [11] reported that increase of renal expression of DMT1 and increase of $\mathrm{Cd}$ accumulation are closely related in the pregnant rat; using rats which suffer from a mutation in the DMT1 gene, Belgrade rat, Chua et al. [3] demonstrated that a deficiency in DMT1 impaired the renal reabsorption of $\mathrm{Fe}^{2+}$ and $\mathrm{Mn}^{2+}$. Other transporters have been suggested to drive the distal reabsorption of heavy metals. Thus, Ducoudret et al. [4] showed that Madin-Darby canine kidney (MDCK) cells, which share some properties of distal nephron cells, expressed a transporter, sensitive to $\mathrm{pH}$, which transports $\mathrm{Zn}^{2+}, \mathrm{Cd}^{2+}$ and $\mathrm{Cu}^{2+}$ but not $\mathrm{Fe}^{2+}, \mathrm{Mn}^{2+}$ or $\mathrm{Co}^{2+}$. Nagao et al. [14] described in this cell line a metal transporter involved in the uptake of $\mathrm{Co}^{2+}, \mathrm{Cu}^{2+}, \mathrm{Ni}^{2+}$, $\mathrm{Pb}^{2+}$ and $\mathrm{Zn}^{2+}$ but not in the uptake of $\mathrm{Fe}^{2+}$ or $\mathrm{Mn}^{2+}$. Unfortunately, in vitro and in vivo data do not yet allow a conclusion as to whether the transporters described in immortalized cell lines are merely modified isoforms of DMT1.

Transport of Bound Forms. During chronic intoxication with heavy metals, liver damage occurs when the capacity of the liver to sequester free forms of metals is exceeded. Then, toxicologically 'inert' bound forms, like metal-metallothionein (MT) and metal-glutathione (GSH), are released into the blood and circulate to the kidneys. Hayashi et al. [9] demonstrated that rat kidney reabsorbs about $50 \%$ of the filtered CdMT complexes. Along the proximal tubule this reabsorption occurs via endocytosis: Erfurt et al. [5] described an internalization of CdMT by endosomes and intracellular storage in immortalized proximal cell lines. Furthermore, parts of the metal-GSH complexes are cleaved by the $\gamma$-glutamyltransferase into Cys-metal conjugates that could be transported by the $\mathrm{Na}^{+}$-amino acid cotransporter. This mech- 


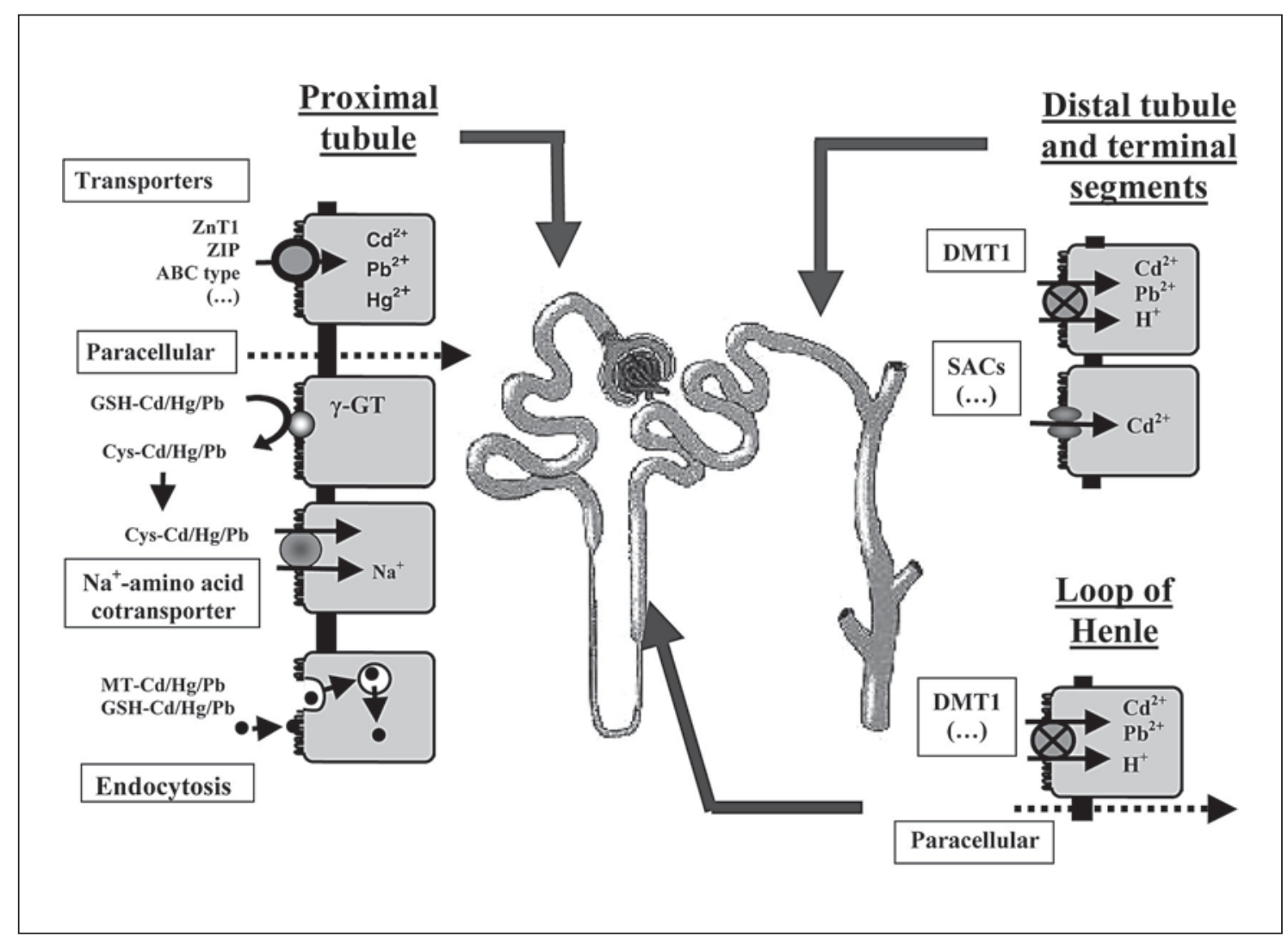

Fig. 1. Diagrammatic representation of putative mechanisms involved in the luminal uptake of heavy metals $(\mathrm{Cd}, \mathrm{Hg}$ and $\mathrm{Pb})$ along the nephron. In the proximal tubule, many transporters of essential metals such as $\mathrm{Zn}^{2+}$ transporters may be involved in the uptake of the free form of toxic metals: zinc transporter 1 (ZnT1), Zrt/Irt-like protein (ZIP) and ATP-binding cassette protein (ABC protein). Reabsorption of metal conjugated with metallothionein (MT) and glutathione $(\mathrm{GSH})$ could also participate in the renal uptake of $\mathrm{Cd}, \mathrm{Hg}$ and $\mathrm{Pb}$ in this segment by endocytosis of the complexed conjugates or by transport of Cys-conjugates through the $\mathrm{Na}^{+}$-amino acid co- transporter after the degradation of GSH by the brush-border enzyme $\gamma$-glutamyltransferase. In the loop of Henle, the main transporter of metals is probably the divalent metal transporter 1 (DMT1), a divalent metal cotransporter coupled to proton transport. Paracellular pathways may be also involved in heavy metal transport along the proximal segment and the loop of Henle. In terminal segments (distal tubule and connecting ducts), the DMT1 and the stretch-activated channels (SACs) could play an important role in the uptake of ionized forms of $\mathrm{Cd}, \mathrm{Hg}$ and $\mathrm{Pb}$. anism has been demonstrated for GSH-Hg and GSH-Cd conjugates [2]. The involvement of the $\mathrm{Na}^{+} / \mathrm{amino}$ acid cotransporter has been suggested by Felley-Bosco and Diezi [6] who demonstrated, using Cys- ${ }^{109} \mathrm{Cd}$ microinjections, that $82 \%$ of $\mathrm{Cys}^{-109} \mathrm{Cd}$ conjugates were reabsorbed by the proximal tubule. Moreover, Gachot et al. [8] showed that $\mathrm{Zn}^{2+}$ enters renal proximal cells via a saturable carrier-mediated system and also chelated to cysteine or histidine via a $\mathrm{Na}^{+} /$amino acid cotransport mechanism. These putative heavy metal uptake pathways are illustrated in the figure 1 .

\section{How Heavy Metals Are Toxic?}

Toxic Form of Heavy Metals. The ionized form of heavy metals is the toxic form. It appears that conjugates and bound forms of filtered heavy metals are not toxic by themselves but that the divalent form of these metals released from the complexes is responsible for the cellular toxicity.

Renal Pathologies due to Heavy Metals. The severity of renal damage depends, first, on the mode of exposure to the heavy metal. The symptoms observed during acute intoxication will differ from those induced by chronic intoxication. This difference could result from 
the concentration and the nature of the toxic metal but also from the form of the heavy metal (free or bound). The work of Liu et al. [12] on $\mathrm{MT}^{-/-}$mice has confirmed that the profile of a $\mathrm{Cd}^{2+}$-induced nephropathy (calciuria, polyuria) is totally different from the profile of a CdMT-induced nephropathy (proximal tubular necrosis and Fanconi syndrome). These data support the idea that during chronic administration the renal toxicity of heavy metals is mainly due to the transport of the filtered conjugate form on the thiol groups of specific or nonspecific proteins whereas during acute administration the free ionized form and the conjugates with short peptides and thiol-amino acids could directly participate in this toxicity.

In the rat, an acute perfusion of $\mathrm{Cd}^{2+}$ caused hypercalciuria, hyperphosphaturia and hypokaliuria without modification of glomerular filtration rate (GFR) [1]. By contrast, a single, 20-fold lower dose of $\mathrm{Pb}^{2+}, \mathrm{Hg}^{2+}$ induced glomerular and tubular damage characterized by a reduced GFR, glycosuria, proteinuria and a rapid obstruction of the tubular system [13], illustrating that the pattern of nephrotoxicity differs between heavy metals. Therefore, $\mathrm{Pb}^{2+}$ and $\mathrm{Hg}^{2+}$ are more dangerous than $\mathrm{Cd}^{2+}$ because they induce an irreversible renal insufficiency even during acute intoxication.

Concerning chronic intoxication, most heavy metals $\left(\mathrm{Cd}^{2+}, \mathrm{Hg}^{2+}, \mathrm{Pb}^{2+}\right)$ induced a Fanconi syndrome characterized by a decrease of the GFR, an increase in urinary flow rate, proteinuria, glycosuria, aminoaciduria and excessive loss of major ions.

Acute Interactions with Transporters and Ion Channels. It has been demonstrated that heavy metals interact with a number of renal transporters. In the proximal tubule, $\mathrm{Cd}^{2+}$ has been shown to decrease phosphate and glucose transport by inhibiting the $\mathrm{NaPi}$ and the $\mathrm{Na} / \mathrm{glu}-$ cose cotransporters respectively. In the terminal segments, $\mathrm{Cd}^{2+}$ exerts a blocking effect on ion channels such as the epithelial calcium channel $(\mathrm{ECaC})$ and the renal outer medullary $\mathrm{K}^{+}$channel (ROMK). $\mathrm{Hg}^{2+}, \mathrm{Pb}^{2+}$ and $\mathrm{Cr}^{3+}$ are also potent blockers of the sulfate transporter, Sat-1. Moreover, because they have the ability to compete with the divalent metal carriers of $\mathrm{Zn}^{2+}$ and $\mathrm{Fe}^{2+}$, toxic heavy metals decrease the reabsorption of these essential oligo-metals. Such competition could induce severe deficiency. For example, the decrease of DMT1-mediated $\mathrm{Fe}^{2+}$ transport in the presence of $\mathrm{Cd}^{2+}$ is probably responsible for the anemia in $\mathrm{Cd}^{2+}$ intoxication.

Cellular Effects. The free forms of heavy metals induce an outer membrane rupture and an uncoupling of mitochondrial respiration. This is the case for $\mathrm{Cd}^{2+}$, which inhibits electron transfer and oxidative phosphorylation, resulting in the release of numerous death signals like reactive oxygen species.

\section{How Can the Kidney Be Protected against Heavy Metal Toxicity?}

It is clear that the danger following exposure to heavy metals comes from the fact that they are accumulated in the renal tissue and poorly excreted in the urine. As discussed above, all the transported forms participate in the toxicity and it is necessary to identify a way to impair their tubular transport, thereby favoring their renal clearance. Concomitantly, decreased heavy metal accumulation could also prevent the induction of binding proteins, inhibit the synthesis of heavy metal-binding protein conjugates and block the delayed deleterious effects observed during chronic intoxication.

Heavy Metal Chelators. For many years, metal chelators have been used to treat heavy metal intoxication. To chelate $\mathrm{Cd}^{2+}, \mathrm{Hg}^{2+}$ and $\mathrm{Pb}^{2+}$, the most commonly used chemicals are either non-sulfured conjugates such as ethylenediaminetetraacetate, triethylenetetramine, deferoxamine and deferiprone or sulfured conjugates such as meso-2,3-dimercaptosuccinic acid and 2,3-dimercapto1-propanesulfonic acid and diethyldithiocarbamate. These molecules have shown real effectiveness in increasing heavy metal elimination through urine. Associated with hemodialysis, the chelators are potent antidotes to cure the acute intoxication with heavy metals such as $\mathrm{Pb}^{2+}, \mathrm{Hg}^{2+}, \mathrm{Cd}^{2+}$. The efficacy of chelating agents is enhanced by amino acids like methionine that facilitate the cell penetration of chelating agents by reducing their ionic character. However, most chelators also complex essential divalent cations or such as $\mathrm{Ca}^{2+}, \mathrm{Mg}^{2+}, \mathrm{Zn}^{2+}, \mathrm{Cu}^{2+}$, $\mathrm{Fe}^{2+}$ and increase their excretion.

D-Cysteine. The compounds cited above may have secondary effects whereas natural compounds, such as amino acids, can be also used as chelator substances for cadmium. Thus, the administration of cysteine to intoxicated animals reduces the amount of cadmium deposition in the kidney by $40 \%$ [16]. In a preliminary study, we investigated whether the $D$-Cys combated cadmium intoxication by increasing its elimination in the urine. Using in vivo ${ }^{109} \mathrm{Cd}$ microinjection in the rat [O.B., unpubl. data], we found that it was possible to increase by 3 -fold the urinary excretion of ${ }^{109} \mathrm{Cd}$ when proximal microinjection was performed in the presence of $D$-Cys. The $D$-Cys form is able to bind $\mathrm{Cd}^{2+}$ but the complex is not 
transported by the $\mathrm{Na}^{+}$-amino acid cotransporter and is not reabsorbed by endocytosis like protein complexes.

Inhibitors and Blockers of Renal Luminal Transport. As stated previously, a few metals, such as $\mathrm{Fe}^{2+}, \mathrm{Co}^{2+}$ and $\mathrm{Zn}^{2+}$, compete with heavy metal transport in renal cells and significantly decrease their reabsorption $[1,18]$. Based on these properties, an increase in the plasma concentration of these metals could induce an increase of the renal clearance of the toxins. Furthermore, 'loop diuretics' like bumetanide could be also used to reduce the paracellular transport of heavy metals in the thick ascending limb [1]. However, the efficiency of these treatments remains to be demonstrated in the intoxicated animal. Moreover, the secondary effects induced by the acute administration of high concentration of essential heavy metals need to be carefully analyzed.

Protection by Zinc. The protective effect of zinc on heavy metal toxicity and especially $\mathrm{Cd}$ toxicity has been known for some years. When $\mathrm{Zn}^{2+}$ is administered with $\mathrm{Cd}^{2+}$ during chronic exposure, it prevents the development of renal dysfunction and Fanconi syndrome [O.B., unpubl. data]. The precise mechanisms involved in protection by zinc are still not well known but an action on apoptosis and oxidative stress is highly suspected.

\section{Conclusion}

It is evident that exposure to heavy metals is potentially harmful. This is due to the high capacity of renal epithelium to transport and accumulate these toxins. Some positive indications emerge from recent studies: new advances in the discovery of therapeutic tools such as blockers of renal reabsorption of heavy metals, or chelators, or cell protectors such as $\mathrm{Zn}^{2+}$, represent progress in finding preventive and/or curative treatment of populations exposed to toxic heavy metals. Nevertheless, many of the mechanisms involved in heavy metal transport and toxicity are still speculative. This review underlines that more in vivo studies are necessary to elucidate the real physiological handling of heavy metals and to develop effective antidotes against acute and chronic intoxication.

\section{Acknowledgment}

We thank David Shirley for helpful criticism of the manuscript.

\section{References}

1 Barbier O, Jacquillet G, Tauc M, Poujeol P, Cougnon M: Acute study of interaction between cadmium, calcium and zinc transport along the rat nephron in vivo. Am J Physiol Renal Physiol 2004;287:F1067-F1075.

-2 Cannon VT, Barfuss DW, Zalups RK: Molecular homology and the luminal transport of $\mathrm{Hg}^{2+}$ in the renal proximal tubule. J Am Soc Nephrol 2000;11:394-402.

3 Chua AC, Morgan EH: Manganese metabolism is impaired in the Belgrade laboratory rat. J Comp Physiol [B] 1997;167:361-369.

4 Ducoudret O, Barbier O, Tauc M, Fuchs M, Poujeol P: Characterization of $\mathrm{Zn}^{2+}$ transport in Madin-Darby canine kidney cells. Biochim Biophys Acta 2003;1611:171-179.

5 Erfurt C, Roussa E, Thevenod F: Apoptosis by $\mathrm{Cd}^{2+}$ or CdMT in proximal tubule cells: Different uptake routes and permissive role of endo/ lysosomal CdMT uptake. Am J Physiol 2003; 285:C1367-C1376.

-6 Felley-Bosco E, Diezi J: Fate of cadmium in rat renal tubules: A microinjection study. Toxicol Appl Pharmacol 1987;91:204-211.

7 Ferguson CJ, Wareing M, Ward DT, Green R, Smith CP, Riccardi D: Cellular localization of divalent metal transporter DMT-1 in rat kidney. Am J Physiol Renal Physiol 2001;280: F803-F814.
8 Gachot B, Tauc M, Morat L, Poujeol P: Zinc uptake by proximal cells isolated from rabbit kidney: Effects of cysteine and histidine. Pflügers Arch 1991;419:583-587.

$\checkmark$ Hayashi T, Terui J, Sudo J: Clearance study for the estimation of glomerular filtration of $\mathrm{Cd}$ following the intravenous bolus of $\mathrm{CdCl}_{2}$ and Cd-saturated metallothionein-II in rats. Biol Pharm Bull 1994;17:557-558.

10 Klaassen CD, Liu J, Choudhuri S: Metallothionein: An intracellular protein to protect against cadmium toxicity. Annu Rev Pharmacol Toxicol 1999;39:267-294.

11 Leazer TM, Liu Y, Klaassen CD: Cadmium absorption and its relationship to divalent metal transporter-1 in the pregnant rat. Toxicol Appl Pharmacol 2002;185:18-24.

12 Liu J, Habeebu SS, Liu Y, Klaassen CD: Acute CdMT injection is not a good model to study chronic $\mathrm{Cd}$ nephropathy: Comparison of chronic $\mathrm{CdCl}_{2}$ and $\mathrm{CdMT}$ exposure with acute CdMT injection in rats. Toxicol Appl Pharmacol 1998;153:48-58.
13 Loghman-Adham M: Renal effects of environmental and occupational lead exposure. Environ Health Perspect 1997;105:928-939.

14 Nagao M, Sugaru E, Kambe T, Sasaki R: Unidirectional transport from apical to basolateral compartment of cobalt ion in polarized MadinDarby canine kidney cells. Biochem Biophys Res Commun 1999;257:289-294.

15 Palmiter RD, Findley SD: Cloning and functional characterization of a mammalian zinc transporter that confers resistance to zinc. EMBO J 1995; 14:639-649.

16 Tandon SK, Prasad S, Singh S: Chelation in metal intoxication: Influence of cysteine or Nacetylcysteine on the efficacy of 2,3-dimercaptopropane-1-sulphonate in the treatment of cadmium toxicity. J Appl Toxicol 2002;22:6771.

17 Thevenod F: Nephrotoxicity and the proximal tubule. Insights from cadmium. Nephron Physiol 2003;93:87-93.

18 Wareing M, Ferguson CJ, Green R, Riccardi $\mathrm{D}$, Smith CP: In vivo characterization of renal iron transport in the anaesthetized rat. J Physiol 2000;524:581-586.

19 Zalups RK: Molecular interactions with mercury in the kidney. Pharmacol Rev 2000;52: $113-143$. 